\title{
Important Things Internists Should Know about Sodium-Glucose Co-Transporter 2 Inhibitors
}

Christopher Oleynick, MD, Pouya Motazedian, MD, Graeme Prosperi-Porta, MD, MASc

Department of Medicine, Cumming School of Medicine, University of Calgary, Calgary, $A B$

Author for Correspondence: Christopher Oleynick: cjoleyni@ucalgary.ca

Received: 18 January 2020; Accepted after revision: 25 May 2020; Published: 26 March 2021.

DOI: https://doi.org/10.22374/cjgim.v16i1.432

\begin{abstract}
Sodium-glucose co-transporter 2 (SGLT-2) inhibitors are a relatively new class of medications available in Canada used in the treatment of type 2 diabetes mellitus (T2DM). There is an abundance of emerging literature that these drugs are not only effective in the treatment of T2DM but also offer robust clinical benefits for renal disease, cardiovascular disease, and congestive heart failure. Despite the clinical benefits, SGLT-2 inhibitors may be underutilized as some physicians are unfamiliar with the medications or are concerned about their side-effect profile. Given the high prevalence of T2DM and the above comorbidities frequently encountered within Internal Medicine, it is important for internists to be familiar with SGLT-2 inhibitors. This is a short article encapsulating important aspects about these medications that we believe internists should know.
\end{abstract}

\section{RÉSUMÉ}

Les inhibiteurs du cotransporteur sodium-glucose de type 2 (SGLT-2) sont une classe relativement nouvelle de médicaments offerts au Canada et utilisés dans le traitement du diabète de type 2 (DT2). Une profusion de nouvelles études montre que ces médicaments sont non seulement efficaces dans le traitement du DT2, mais qu'ils offrent également de solides avantages cliniques pour les maladies rénales, les maladies cardiovasculaires et l'insuffisance cardiaque congestive. Malgré ces avantages cliniques, les inhibiteurs du SGLT-2 sont peut-être sous-utilisés, car certains médecins ne connaissent pas ces médicaments ou s'inquiètent de leur profil d'effets secondaires. Étant donné la forte prévalence du DT2 et les affections comorbides susmentionnées fréquemment rencontrées en médecine interne, il est important que les internistes connaissent bien les inhibiteurs du SGLT-2. Voici un court article qui résume les aspects importants de ces médicaments que les internistes devraient connaître.

\section{Sodium-Glucose Co-Transporter 2 Inhibitors Are a Relatively New Class of Drugs Used in the Treatment of Type 2 Diabetes}

Sodium-glucose co-transporter 2 (SGLT-2) inhibitors inhibit glucose re-absorption in the proximal convoluted tubule of the kidney, thereby promoting glucosuria and reducing serum glucose in a mechanism of action that is independent of insulin. They yield a modest reduction in hemoglobin Alc (HbAlc) between 0.5 and $1 \%$, and cause a sustained average weight loss of $2-3 \mathrm{~kg}$ after initiation. ${ }^{1,2}$ Although metformin is still recommended for first-line pharmacotherapy for type 2 diabetes mellitus (T2DM), multiple guidelines including Diabetes Canada are recommending 
SGLT-2 inhibitors as a second-line treatment for many patients. Renal function is an important factor when initiating these medications as their use is contraindicated when used for glycemic control with an estimated glomerular filtration rate (eGFR) of $<30 \mathrm{~mL} / \mathrm{min} / 1.73 \mathrm{~m}^{2}$ and should be discontinued if a patients' renal function deteriorates below this range. ${ }^{2,3}$ Although these agents show promise for potential treatment of type 1 diabetes, further studies are needed to evaluate their safety and efficacy for this patient population. ${ }^{4}$ Canagliflozin, empagliflozin, and dapagliflozin, first introduced in 2014, are the most common drugs of this class available in Canada.

\section{Sodium-Glucose Co-Transporter 2 Inhibitors Reduce Major Adverse Renal Outcomes in Patients with Type 2 Diabetes}

SGLT-2 inhibitors have robust and well-documented renal protective effects although the mechanism for this protection has not been entirely understood. In addition to the improvement of risk factors such as glycemic control, blood pressure, and bodyweight, some experts hypothesize that renal protection may center on reduced expenditure of energy in the proximal tubule, thereby reducing the susceptibility of tubular cells to acute volume- or ischemic-related insults.5,6 SGLT-2 inhibitors reduce the progression of renal disease by $45 \%$ (HR 0.55 [95\% CI $0.48-0.64], \mathrm{P}=0.0001$ ) and reduce the risk of dialysis, transplant, or death from renal causes by $33 \%$ (HR 0.67 [95\% CI 0.52-0.86], $\mathrm{P}=0.0019) .6,7$ This benefit was seen across all patients with an eGFR $>30 \mathrm{~mL} / \mathrm{min} / 1.73 \mathrm{~m}^{2}$ and across all albuminuria subgroups. Internists should strongly consider the use of SGLT- 2 inhibitors in patients with T2DM and evidence of renal disease who have appropriate renal function.

\section{Sodium-Glucose Co-Transporter 2 Inhibitors Reduce Worsening of Congestive Heart Failure,} Cardiovascular Death, and Admissions to Hospital

The recent DAPA-HF trial demonstrated that in patients with symptomatic $\mathrm{CHF}$ and reduced left ventricular ejection fraction (LVEF) $<40 \%$, dapagliflozin reduced the worsening of CHF or cardiovascular death by $26 \%$ (HR 0.74 [ $95 \%$ CI 0.65-0.85], $\mathrm{P}=$ 0.00001 ) and the worsening of CHF including hospitalization by $30 \%$ (HR 0.70 [95\% CI 0.59-0.83], $\mathrm{P}=0.00003$ ), irrespective of their diabetic status. ${ }^{8}$ A meta-analysis comparing the EMPAREG OUTCOME (empagliflozin), CANVAS (canagliflozin), and DECLARE-TIMI-58 (dapagliflozin) trials noted similar results, that is, SLGT-2 inhibitors reduce hospitalization for CHF by $31 \%$ (HR 0.69 [95\% CI $0.71-0.84$ ], P = 0.0001), irrespective of LVEF.7 The mechanism of action for improving outcomes for patients with CHF is thought to be secondary to the renal protective effects coupled with natriuresis of these drugs, thereby reducing the risk for cardiac decompensation ${ }^{7,8}$ Internists should strongly consider the use of SGLT-2 inhibitors in patients with T2DM and CHF, and dapagliflozin for patients with CHF and an $\mathrm{LVEF}<40 \%$, regardless of their diabetic status.

\section{Sodium-Glucose Co-Transporter 2 Inhibitors Reduce Major Adverse Cardiac Events in Patients with Type 2 Diabetes and Coronary Artery Disease}

Many studies have examined the role of SGLT-2 inhibitors in cardiac risk reduction. The most comprehensive meta-analysis to date, published last year by Zelniker et al. inclusive of empagliflozin, canagliflozin, and dapagliflozin, demonstrates that SGLT-2 inhibitors reduce the incidence of cardiovascular death, myocardial infarction, or stroke by $11 \%$ (HR 0.89 [95\% CI 0.83-0.96], $\mathrm{P}=0.0014) .{ }^{7}$ It is important to note, however, that this benefit was seen exclusively in patients with preexisting coronary artery disease (CAD), and there was no statistically significant effect observed in patients without atherosclerotic cardiovascular disease. ${ }^{7}$ Nonetheless, given this modest effect and high prevalence of patients that have both comorbidities, internists should consider the use of SGLT-2 inhibitors in patients with T2DM and documented CAD.

\section{Internists Should Be Aware of the Adverse Effects Profile of Sodium-Glucose Co-Transporter 2 Inhibitors}

The side-effect profile of SLGT-2 inhibitors may cause some hesitation amongst some clinicians before prescribing them. Toe/foot amputations, diabetic ketoacidosis (DKA), Fournier's gangrene, bone fractures, and acute kidney injuries are significant adverse effects that clinicians are often concerned about; however, a recent meta-analysis by Donnan et al. analyzing 109 articles found that SGLT-2 inhibitors as a class were not associated with a risk of harm for these complications over placebo. ${ }^{3}$ Urinary tract infections were the most frequently cited adverse effect, but even this did not occur more frequently than placebo across the drug class, except in the dapagliflozin subgroup with an increased relative risk of 1.21 (95\% CI $\left.1.02-1.43, \mathrm{I}^{2}=0.0 \%\right)^{3}$ Although uncommon, SGLT-2 inhibitors do increase the risk of developing euglycemic DKA, and clinicians should have a low threshold to investigate this in patients on these drugs who present clinically unwell. ${ }^{9}$ Although these studies appear to be reassuring, their wide confidence intervals suggest that further research is needed to rule out significant harm more definitively. SGLT-2 inhibitors are generally very well-tolerated medications that offer significant clinical benefits, but they should be used with caution in patients with frequent urinary tract infections, foot ulcerations, or significant factors that may predispose the patient to DKA. 


\section{Internists Should Be Aware of Situations Where They Should Hold Back Sodium-Glucose Co-Transporter 2 Inhibitors}

Due to the propensity of SGLT-2 inhibitors to cause mild dehydration through diuresis, they can contribute to worsening pre-renal injury and should be held back in most patients admitted to hospital with acute kidney injury (AKI) or those who are seriously ill. ${ }^{10}$ SGLT-2 inhibitors have been associated with increased rates of perioperative ketoacidosis and $\mathrm{AKI}$, and it is suggested that empagliflozin, canagliflozin, and dapagliflozin be stopped 3 days before elective surgery to reduce the risk of developing the abovementioned complications. ${ }^{11,12}$ These medications can be reinitiated after surgery when the patient's oral intake has returned to baseline. In the outpatient setting, clinicians should also be mindful to add SGLT-2 inhibitors to their patient's sick-day medication list and ensure patients temporarily stop taking these medications when they feel sick with any condition causing decreased oral intake or dehydration. ${ }^{10}$

\section{Funding}

There is no funding associated with this manuscript.

\section{Competing Interests}

The authors declare that they have no financial or nonfinancial competing interests related to this manuscript.

\section{Author's Contributions}

CO, PM, and GPP prepared the manuscript. All authors read and approved the final manuscript.

\section{Acknowledgements}

The authors have no acknowledgements.

\section{References}

1. Pinto L, Rados D, Remonti L, Kramer C, Leitao C, Gross J. Efficacy of SGLT2 inhibitors in glycemic control, weight loss and blood pressure reduction: A systematic review and meta-analysis. Diabetol Metab Syndr. 2015;7 (Suppl 1):A58. https://dx.doi.org/10.1186\%2F1758-5996-7-S1-A58

2. Liu XY, Zhang N, Chen R, Zhao JG, Yu P. Efficacy and safety of sodiumglucose cotransporter 2 inhibitors in type 2 diabetes: A meta-analysis of randomized controlled trials for 1 to 2 years. J Diabetes Complications. 2015;29(8):1295-303. http://dx.doi.org/10.1016/j.jdiacomp.2015.07.011

3. Donnan JR, Grandy CA, Chibrikov E, Marra CA, Aubrey-Bassler K, Johnston $\mathrm{K}$, et al. Comparative safety of the sodium glucose co-transporter 2 (SGLT2) inhibitors: A systematic review and meta-analysis. BMJ Open. 2019;9(1): 1-15. http://dx.doi.org/10.1136/bmjopen-2018-022577

4. Taylor SI, Blau JE, Rother KI, Beitelshees AL. SGLT2 inhibitors as adjunctive therapy for type 1 diabetes: Balancing benefits and risks. Lancet Diabetes Endocrinol. 2019;7(12):949-58. http://dx.doi.org/10.1016/ S2213-8587(19)30154-8

5. Kashihara N, Kidokoro K, Kanda E. Renoprotective effects of sodiumglucose cotransporter-2 inhibitors and underlying mechanisms. Curr Opin Nephrol Hypertens. 2020;29(1):112-18. http://dx.doi.org/10.1097/ MNH.0000000000000561

6. Neuen BL, Young T, Heerspink HJL, Neal B, Perkovic V, Billot L, et al. SGLT2 inhibitors for the prevention of kidney failure in patients with type 2 diabetes: A systematic review and meta-analysis. Lancet Diabetes Endocrinol. 2019;7(11):845-54. http://dx.doi.org/10.1016/ S2213-8587(19)30256-6

7. Zelniker TA, Wiviott SD, Raz I, Im K, Goodrich EL, Bonaca MP, et al. SGLT2 inhibitors for primary and secondary prevention of cardiovascular and renal outcomes in type 2 diabetes: A systematic review and meta-analysis of cardiovascular outcome trials. Lancet. 2019;393(10166):31-9. http://dx.doi .org/10.1016/S0140-6736(18)32590-X

8. McMurray JJV, Solomon SD, Inzucchi SE, Køber L, Kosiborod MN, Martinez FA, et al. Dapagliflozin in patients with heart failure and reduced ejection fraction. N Engl J Med. 2019;381:1995-2008. http://dx.doi.org/10.1056/ NEJMoa1911303

9. Yu X, Zhang S, Zhang L. Newer perspectives of mechanisms for euglycemic diabetic ketoacidosis. Int J Endocrinol. 2018;2018:7074868. http://dx.doi .org/10.1155/2018/7074868

10. Lipscombe L, Booth G, Butalia S, Dasgupta K, Eurich DT, Goldenberg R, et al. Pharmacologic glycemic management of type 2 diabetes in adults. Can J Diabetes. 2018;42:S88-013. http://dx.doi.org/10.1016/j .jcjd.2017.10.034

11. Milder DA, Milder TY, Kam PCA. Sodium-glucose co-transporter type-2 inhibitors: Pharmacology and peri-operative considerations. Anaesthesia. 2018;73(8):1008-18. http://dx.doi.org/10.1111/anae.14251

12. U.S. Food and Drug Administration. SGLT2 inhibitor update [Internet]. FDA Drug Safety Communication; 2020. Available from: https://www. fda.gov/drugs/drug-safety-and-availability/fda-revises-labels-sglt2inhibitors-diabetes-include-warnings-about-too-much-acid-blood-andserious 